\title{
The association between serum albumin and depression in chronic liver disease may differ by liver histology
}

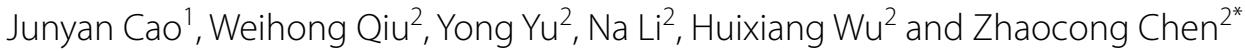

\begin{abstract}
Background: There are conflicting results regarding the association between chronic liver disease (CLD) and depression and the underlying biological mechanisms are lack of investigation. To address the impact of depression and its effects on the management of CLD, its biological marker is critical to be identified. The present study explored the association between serum albumin and depression in CLD patients and whether the association varied in different liver histological stages.

Methods: Based on the United States National Health and Nutrition Examination Survey 2017-2018, the data of serum albumin and depressive symptoms from 627 participants with CLD were used. Depression symptoms were assessed with the nine-item Patient Health Questionnaire (PHQ-9). We used multivariate linear regression to evaluate the association between serum albumin and PHQ-9 scores. Stratified analysis was performed according to the liver histology examined by vibration controlled transient elastography.

Results: Serum albumin level was inversely associated with PHQ-9 scores in the multivariate regression model after adjusting for mainly potential confounders $(\beta=-1.113,95 \% \mathrm{Cl}:-2.065$ to $-0.162, P=0.0221)$. In the subgroup analysis stratified by gender, controlled attenuation parameter (CAP) and liver stiffness measurement (LSM), the inverse association remained significant in female $(\beta=-2.002,95 \% \mathrm{Cl}:-3.515$ to $-0.489, P=0.0100)$, patients with $\mathrm{CAP}<274 \mathrm{~dB} / \mathrm{m}(\beta=-2.215,95 \% \mathrm{Cl}:-3.621$ to $-0.808, P=0.0023)$ and patients with $\mathrm{LSM} \geq 8.2 \mathrm{kPa}(\beta=-4.074$, $95 \% \mathrm{Cl}:-6.237$ to $-1.911, P=0.0003)$. Moreover, the association was much stronger when the serum albumin was higher than $3.4 \mathrm{~g} / \mathrm{dL}$ among patients with $\mathrm{LSM} \geq 8.2 \mathrm{kPa}(\beta=-4.835,95 \% \mathrm{Cl}:-7.137$ to $-2.533, P<0.0001)$.
\end{abstract}

Conclusion: Our study revealed an inverse association between serum albumin and depression in CLD patients and this association differed according to liver histological changes. Serum albumin could be a warning marker for depressive symptoms in CLD patients. It is essential for taking corresponding intervention strategies.

Keywords: Serum albumin, Depression, Chronic liver disease, Liver histology, Vibration controlled transient elastography

*Correspondence: chenzhc5@mail.sysu.edu.cn

${ }^{2}$ Department of Rehabilitation Medicine, The Third Affiliated Hospital

of Sun Yat-sen University, Sun Yat-sen University, 600 Tianhe Road,

Guangzhou 510630, China

Full list of author information is available at the end of the article

\section{Introduction}

Chronic liver disease (CLD) has been a serious economic burden to the society with a high prevalence and incidence [1]. It was estimated that at least 844 million people worldwide suffered from CLD and there were 2 million deaths per year [2]. In addition to progressive destruction of the liver parenchyma, multiple 
extrahepatic manifestations such as depression, fatigue, and compromised health-related quality of life were present in CLD $[3,4]$.

CLD has been associated with depression. A study showed that the prevalence of depression in chronic hepatitis $\mathrm{B}(\mathrm{CHB})$ and chronic hepatitis $\mathrm{C}(\mathrm{CHC})$ patients was significantly higher than healthy participants [5]. Likewise, it was reported that the percentage of $\mathrm{CHB}$ patients suffering from severe depression was higher than hepatitis B surface antigen carriers and healthy controls [6]. In another study utilizing National Inpatient Sample data, patients with alcohol-related liver disease (ALD) were 1.83 times more likely to have depression compared to those with chronic liver diseases not caused by alcohol [7]. Similar finding was found when they compared patients with ALD and those without liver diseases (OR 1.14). Another increasingly important cause of CLD is non-alcoholic fatty liver disease (NAFLD). Relatively high prevalence of depression has been identified in patients with NAFLD in several population-based studies [8-10]. However, most studies above focused on the association between depression and CLD, while the underlying biological mechanisms are lack of investigation.

Depression was expected to be the world's third leading cause of disability according to the Global Burden of Disease 2017 [11]. In many patients with depression, their adherence to dietary intake and exercise is poor [9]. Moreover, depression is along with poor compliance with medication for general chronic illnesses [12]. To address the impact of depression and its effects on the management of CLD, the biological marker for concomitant depressive symptoms is critical to be identified and promptly intervened in patients with CLD.

Serum albumin is the most abundant protein in human blood plasma and is essential for the maintenance of $\mathrm{pH}$, osmotic pressure and the transportation of fatty acids. Albumin level has been reported to be significantly lower in patients with major depressive disorders [13]. A study has demonstrated that low level of serum albumin is associated with long-term depressive symptoms in stroke surviving elderly individuals [14]. For the patients with schizophrenia, serum albumin level was significantly lower and decreased albumin level was associated with the depressive score of Positive and Negative Syndrome Scale [15]. Serum albumin level was also found to be closely associated with depressive symptoms in patients with maintenance hemodialysis [16].

To date, however, no study has examined the relationship between serum albumin level and depression in CLD patients. Previous studies have stated that depression tended to be associated with histological changes of liver diseases [10, 17]. Vibration controlled transient elastography (VCTE) is one of the most validated techniques suitable for assessing liver histology in large populations [18]. Therefore, we conceived to explore the associations between serum albumin and depression in CLD patients and whether this association differ by the liver histology, using the data of National Health and Nutrition Examination Survey (NHANES) from 2017 to 2018. If there is an independent association between serum albumin and depression, it may suggest that serum albumin is a useful biomarker in identifying CLD patients at risk of developing depressive symptoms.

\section{Materials and methods Study population}

The NHANES was a cross-sectional population-based national survey that collected information of the health and nutrition in the USA in 2-yearcycles. Researchers throughout the world can access to the survey data online. Details regarding the design and operation of the datasets were provided at www.cdc.gov/nchs/nhanes/. The survey was approved by the ethics review board of the National Center for Health Statistics and written informed consent was obtained from all participants or their guardians.

Five categories of CLD were included: $\mathrm{CHB}$ (positive hepatitis $\mathrm{B}$ virus surface antigen), $\mathrm{CHC}$ (positive hepatitis $C$ virus $\mathrm{RNA}$ ), chronic hepatitis $\mathrm{E}$ (CHE, positive hepatitis E virus IgM), NAFLD and ALD. Although hepatitis $\mathrm{E}$ virus infection is usually asymptomatic, it can progress to chronicity and fibrosis especially in individuals with underlying liver diseases or immunodeficiency [19]. Therefore, we have also included CHE in this study. NAFLD was defined by the absence of any other causes of CLD and presence of elevated liver enzymes (alanine aminotransferase (ALT) $>40 \mathrm{U} / \mathrm{L}$ or aspartate aminotransferase (AST) $>37 \mathrm{U} / \mathrm{L}$ in men and ALT or AST $>31 \mathrm{U} / \mathrm{L}$ in women). ALD was defined as a significant alcohol use of $>30 \mathrm{~g} /$ day for men and $>20 \mathrm{~g} /$ day for women over past 12 months and the presence of elevated liver enzymes.

Of all the 679 participants with CLD aged $\geq 18$ (from 18 to 80 years) with all serum albumin and nineitem Patient Health Questionnaire (PHQ-9) data from NHANES 2017-2018, 627 participants (348 men and 279 women, $43.6 \pm 16.2$ years for men and $50.7 \pm 16.8$ years for women) remained for the final analysis after exclusion of 52 participants with cancer or malignancy.

\section{Variables}

In this study, the independent variable was serum albumin. Its concentration was measured using the bichromatic digital endpoint method on a Roche Cobas 6000 (c501 module) analyzer. In the reaction, albumin bound with dye bromocresol purple to form a complex. The 
absorbance was tested at $600 \mathrm{~nm}$. The secondary wavelength was $700 \mathrm{~nm}$. The dependent variable was depressive symptom. It was assessed using the PHQ-9. Each of the nine items was scored by a 4-point response ranging from 0 to 3 and the sum-score was used as a severity measure.

NHANES provided information about age, gender, race, body mass index (BMI), alcohol consumption, serum total bilirubin (TB), ALT, AST, antidepressant use, controlled attenuation parameter (CAP) and liver stiffness measurement (LSM). Alcohol consumption was estimated according to self-reported amount and frequency of alcohol use in the previous year. Antidepressant use including selective serotonin reuptake inhibitors, tricyclics, monoamine oxidase inhibitors, tetracyclics, serotonin and norepinephrine reuptake inhibitors and miscellaneous antidepressants was determined through the in-home questionnaire. VCTE is a non-invasive tool that can be used to measure CAP and LSM, which is available for assessing the existence of liver steatosis and fibrosis, respectively. In the NHANES 2017-2018 cycle, VCTE was implemented on FibroScan ${ }^{\circledR} 502$ Touch model (M Probe; XL Probe; Echosens, Paris, France). According to a recent study, liver steatosis was defined with $C A P \geq 274 \mathrm{~dB} / \mathrm{m}$, and liver fibrosis was defined with LSM $\geq 8.2 \mathrm{kPa}$ [20]. Although liver steatosis was more common in NAFLD, it could also occur in chronic hepatitis [21, 22] and ALD [23]. According to published metaanalysis and prospective studies, the liver stiffness cut-off was $8.2 \mathrm{kPa}$ for $\mathrm{F} \geq 3$ in $\mathrm{CHB}$ [24], whereas, in NAFLD, $8.2 \mathrm{kPa}$ was the cut-off for $\mathrm{F} \geq 2$ [20]. NAFLD had the highest proportion in our study population. Therefore, we chose $8.2 \mathrm{kPa}$ as the threshold of liver fibrosis, ensuring that the participants with LSM $\geq 8.2 \mathrm{kPa}$ do have liver fibrosis using this relative high value. Because the CLD population of our study was relatively small and there was only a total of 134 participants with $L S M \geq 8.2 \mathrm{kPa}$, hence they were not divided with advanced fibrosis and cirrhosis.

\section{Statistical analysis}

All estimates were calculated using NHANES sample weights. Categorical variables were described by frequency distributions. Continuous variables were described by means \pm standard deviation. Weighted linear regression models (continuous variables) and weighted chi-square tests (categorical variables) were used to calculate differences between different groups categorized by quintile of serum albumin. $P<0.05$ was considered statistically significant. Multivariate linear regression models were used to evaluate the association between serum albumin and PHQ-9 scores in CLD patients. Age, gender and race were adjusted for the first model. The second model was further adjusted for BMI, alcohol consumption, TB, ALT, AST, antidepressant use, CAP and LSM. These covariates were selected either based on literature knowledge or if they changed the exposure coefficient by more than $10 \%$. The category of CLD was not included as a covariate because it didn't changed the exposure coefficient more than $10 \%$. All statistical analyses were performed with R (http:// www.R-project.org, The R Foundation) and EmpowerStats software (http://www.empowerstats.com, X\&Y Solutions, Inc., Boston, MA).

\section{Results}

Among the 627 participants included in our analysis, 21 (3.35\%) were participants with $\mathrm{CHB}, 41$ (6.54\%) were participants with $\mathrm{CHC}, 55$ (8.77\%) were participants with CHE, 259 (41.31\%) were participants with NAFLD and 251 (40.03\%) were participants with ALD. The weighted sociodemographic and medical characteristics of the participants subclassified based on serum albumin quintiles were shown in Table 1 . There were significant differences in baseline characteristics between the serum albumin quintiles including age, gender, BMI, alcohol consumption, CAP, LSM, TB, PHQ-9 scores and antidepressant use. It suggested that the values or the distributions were not the same for the quintiles of serum albumin and these variables should be considered as covariates while testing the trend between quintiles of serum albumin.

Three weighted univariate and multivariate linear regression models were constructed. In the unadjusted model, we observed an inverse association between serum albumin and PHQ-9 scores. Similar results were found in model 2 (adjustment for age, gender, race) $(\beta=-1.374,95 \% \mathrm{CI}:-2.281$ to $-0.466, P=0.0031)$ and model 3 (fully adjusted model) $(\beta=-1.113,95 \%$ CI: -2.065 to $-0.162, P=0.0221$ ). Stratified by quintile of serum albumin, the trend test remained significant between them $(P$ for trend $=0.009)$ (Table 2$)$. Weighted generalized additive model and smooth curve fitting were also performed to evaluate the associations between them (Fig. 1).

In the subgroup analysis (Table 3), serum albumin was significantly associated with lower PHQ-9 scores in female $(\beta=-2.002,95 \% \mathrm{CI}:-3.515$ to -0.489 , $P=0.0100)$, patients with $\mathrm{CAP}<274 \mathrm{~dB} / \mathrm{m}(\beta=-2.215$, 95\% CI: -3.621 to $-0.808, P=0.0023)$ and patients with $\mathrm{LSM} \geq 8.2 \mathrm{kPa}(\beta=-4.074,95 \% \mathrm{CI}:-6.237$ to -1.911 , $P=0.0003)$. Smooth curve fittings and generalized additive models used to characterize the relationship between serum albumin and PHQ-9 scores stratified by gender, CAP and LSM were shown in Figs. 2, 3 and 4. Among patients with $L S M \geq 8.2 \mathrm{kPa}$, there was a point of inflection at $3.4 \mathrm{~g} / \mathrm{dL}$ of serum albumin identified using a 
Table 1 The characteristics of participants

\begin{tabular}{|c|c|c|c|c|c|c|c|}
\hline Serum albumin & All $(n=627)$ & Q1 $(n=86)$ & Q2 $(n=110)$ & Q3 $(n=135)$ & Q4 $(n=154)$ & Q5 $(n=142)$ & $P$-value \\
\hline Age (years) & $44.03 \pm 16.31$ & $48.56 \pm 15.63$ & $46.98 \pm 16.27$ & $47.67 \pm 16.00$ & $42.14 \pm 16.64$ & $39.84 \pm 15.14$ & $<0.0001$ \\
\hline Gender (\%) & & & & & & & $<0.0001$ \\
\hline Male & 58.12 & 28.40 & 37.00 & 61.84 & 68.25 & 70.74 & \\
\hline Female & 41.88 & 71.60 & 63.00 & 38.16 & 31.75 & 29.26 & \\
\hline Race (\%) & & & & & & & 0.5458 \\
\hline White & 60.03 & 55.08 & 55.75 & 63.56 & 60.62 & 61.68 & \\
\hline Black & 8.58 & 13.97 & 11.00 & 8.51 & 7.53 & 5.90 & \\
\hline Hispanic & 20.04 & 19.54 & 25.65 & 18.98 & 17.84 & 20.01 & \\
\hline Other & 11.36 & 11.41 & 7.60 & 8.94 & 14.00 & 12.42 & \\
\hline BMI $\left(\mathrm{kg} / \mathrm{m}^{2}\right)$ & $31.89 \pm 7.91$ & $35.24 \pm 11.22$ & $34.40 \pm 8.89$ & $32.29 \pm 7.66$ & $31.66 \pm 5.92$ & $29.01 \pm 6.11$ & $<0.0001$ \\
\hline Alcohol consumption (\%) & & & & & & & 0.0040 \\
\hline Never & 7.21 & 6.47 & 8.69 & 6.09 & 4.08 & 10.45 & \\
\hline Mild & 38.20 & 44.12 & 28.16 & 37.13 & 48.75 & 31.69 & \\
\hline Moderate & 42.48 & 33.61 & 57.39 & 42.39 & 37.40 & 43.28 & \\
\hline Excessive & 12.01 & 15.80 & 5.75 & 14.40 & 9.77 & 14.58 & \\
\hline CAP (\%) & & & & & & & 0.0029 \\
\hline$<274 \mathrm{~dB} / \mathrm{m}$ & 38.42 & 51.23 & 24.70 & 33.99 & 37.54 & 43.86 & \\
\hline$\geq 274 \mathrm{~dB} / \mathrm{m}$ & 61.58 & 48.77 & 75.30 & 66.01 & 62.46 & 56.14 & \\
\hline LSM (\%) & & & & & & & 0.0290 \\
\hline$<8.2 \mathrm{kPa}$ & 79.96 & 68.71 & 77.30 & 78.01 & 82.13 & 85.60 & \\
\hline$\geq 8.2 \mathrm{kPa}$ & 20.04 & 31.29 & 22.70 & 21.99 & 17.87 & 14.40 & \\
\hline $\operatorname{ALT}(\mathrm{U} / \mathrm{L})$ & $51.93 \pm 29.72$ & $47.52 \pm 24.97$ & $48.59 \pm 29.16$ & $53.61 \pm 36.10$ & $53.63 \pm 29.46$ & $52.98 \pm 27.16$ & 0.4032 \\
\hline $\mathrm{AST}(\mathrm{U} / \mathrm{L})$ & $40.79 \pm 25.06$ & $44.79 \pm 31.25$ & $40.41 \pm 24.68$ & $39.55 \pm 23.56$ & $37.86 \pm 18.67$ & $42.80 \pm 27.86$ & 0.2255 \\
\hline $\mathrm{TB}(\mathrm{mg} / \mathrm{dL})$ & $0.52 \pm 0.29$ & $0.38 \pm 0.20$ & $0.43 \pm 0.23$ & $0.54 \pm 0.26$ & $0.53 \pm 0.31$ & $0.62 \pm 0.30$ & $<0.0001$ \\
\hline PHQ-9 score & $3.25 \pm 3.86$ & $4.42 \pm 4.45$ & $3.61 \pm 3.96$ & $3.88 \pm 4.56$ & $2.76 \pm 3.58$ & $2.58 \pm 2.98$ & 0.0008 \\
\hline Antidepressant use (\%) & & & & & & & 0.0103 \\
\hline+ & 11.13 & 17.70 & 16.69 & 14.09 & 7.97 & 6.27 & \\
\hline- & 88.87 & 82.30 & 83.31 & 85.91 & 92.03 & 93.73 & \\
\hline
\end{tabular}

Mean \pm SD for continuous variables, $P$-value was calculated by weighted linear regression

$\%$ for categorical variables, $P$-value was calculated by weighted chi-square test

$B M I$ body mass index, $T B$ total bilirubin, $A L T$ alanine aminotransferase, $A S T$ aspartate aminotransferase, $P H Q-9$ nine-item Patient Health Questionnaire, $C A P$ controlled attenuation parameter, LSM liver stiffness measurement

two-piecewise linear regression model. The association was much stronger when the serum albumin was higher than $3.4 \mathrm{~g} / \mathrm{dL}(\beta=-4.835,95 \%$ CI: -7.137 to -2.533 , $P<0.0001)$.

\section{Discussion}

In this study, we used the representative samples of NHANES 2017-2018 to evaluate the association between serum albumin and depressive symptoms in CLD patients. Our results suggested that serum albumin was inversely associated with PHQ-9 scores in CLD patients. To be more specific, this association was significant in female, patients with $\mathrm{CAP}<274 \mathrm{~dB} / \mathrm{m}$ and patients with $\mathrm{LSM} \geq 8.2 \mathrm{kPa}$.

Several studies have demonstrated conflicting results regarding the association between CLD and depression.
Elwing et al. found that subjects with nonalcoholic steatohepatitis had significantly elevated PHQ-9 scores and increased lifetime rates of major depression disease [17]. Weinstein et al. reported increased prevalence of depression in patients with NAFLD and those with $\mathrm{CHC}$ [8]. In contrast, a study assessing the association between four types of CLD (CHB, CHC, ALD and NAFLD) with depression showed that depression was only strongly associated with $\mathrm{CHC}$ [25]. Additionally, a case-control study provided insignificant association between NAFLD and depression [26]. These conflicting data raised the possibility that there might be an unrevealing independent factor associated with depression in CLD patients, rather than CLD itself. In the present study, we found that serum albumin was inversely associated with depression in CLD patients. This finding was consistent with previous studies where the association between serum 
Table 2 Association between serum albumin level ( $\mathrm{g} / \mathrm{dL}$ ) and PHQ-9 score

\begin{tabular}{clll}
\hline & $\begin{array}{l}\text { Unadjusted model } \\
\boldsymbol{\beta} \mathbf{( 9 5 \%} \mathbf{C l})\end{array}$ & $\begin{array}{l}\text { Model 1 } \\
\boldsymbol{\beta} \mathbf{( 9 5 \% ~ C l )}\end{array}$ & $\begin{array}{l}\text { Model 2 } \\
\boldsymbol{\beta} \mathbf{( 9 5 \% ~ C l )}\end{array}$ \\
\hline Albumin & $-1.776(-2.628$, & $-1.374(-2.281$, & $-1.113(-2.065$, \\
& $-0.924)$ & $-0.466)$ & $-0.162)$ \\
P-value & $<0.0001$ & 0.0031 & 0.0221 \\
Albumin (quintile) & & \\
Q1 & Reference & Reference & Reference \\
Q2 & $-0.812(-1.957,0.334)$ & $-0.686(-1.829,0.457)$ & $-0.960(-2.084$, \\
& & & $0.163)$ \\
Q3 & $-0.534(-1.634,0.566)$ & $-0.203(-1.322,0.915)$ & $-0.441(-1.551$, \\
& & & $0.670)$ \\
Q4 & $-1.659(-2.687$, & $-1.286(-2.347$, & $-1.281(-2.353$, \\
& $-0.632)$ & $-0.226)$ & $-0.208)$ \\
Q5 & $-1.834(-2.854$, & $-1.414(-2.475$, & $-1.462(-2.564$, \\
& $-0.815)$ & $-0.354)$ & $-0.359)$ \\
Pfor trend & $<0.001$ & 0.003 & 0.009 \\
\hline
\end{tabular}

Unadjusted model: no covariates were adjusted

Model 1: age, gender and race were adjusted

Model 2: age, gender, race, body mass index, alcohol consumption, total bilirubin, alanine aminotransferase, aspartate aminotransferase, antidepressant use, controlled attenuation parameter and liver stiffness measurement were adjusted

albumin and depression has been observed in elderly stroke survivors [14], patients with schizophrenia [15], HIV-infected persons [27] and individuals with a recent suicide attempt [28].
The etiology of depression is related to an excess of free-radicals, such as reactive oxygen and nitrogen species, which impose increased oxidative stress on the antioxidants defense system [29]. Abnormal levels of oxidative product have been found in peripheral blood [30], cerebrospinal [31] and postmortem brains [32] of the patients with depression. Aside from the property of protein binding and transportation, albumin is recognized to act as an antioxidant by scavenging free-radicals [33]. It has been found to be capable of binding iron and inhibiting lipid peroxidation [34]. These studies may indicate that it is through imbalance between lower antioxidants and increased oxidative stress that the protective antioxidant system fails and the decreased serum albumin influence the extent of depressive symptoms.

Although several biochemical indices such as US fatty liver index, hepatic steatosis index and fibrosis-4 index were reliable to assess the liver histological changes [35-37], they did not have an absolute cut-off and might misclassify the presence of steatosis or fibrosis. In comparison, VCTE is a new technology which is validated and feasible for large-scale examination and follow-ups [18]. The NHANES data from 2017 to 2018 adopted this kind of quantitative radiological information, producing more reliable estimates of both steatosis and fibrosis. This is the major strengths of our present study. To our knowledge, it remained rare to

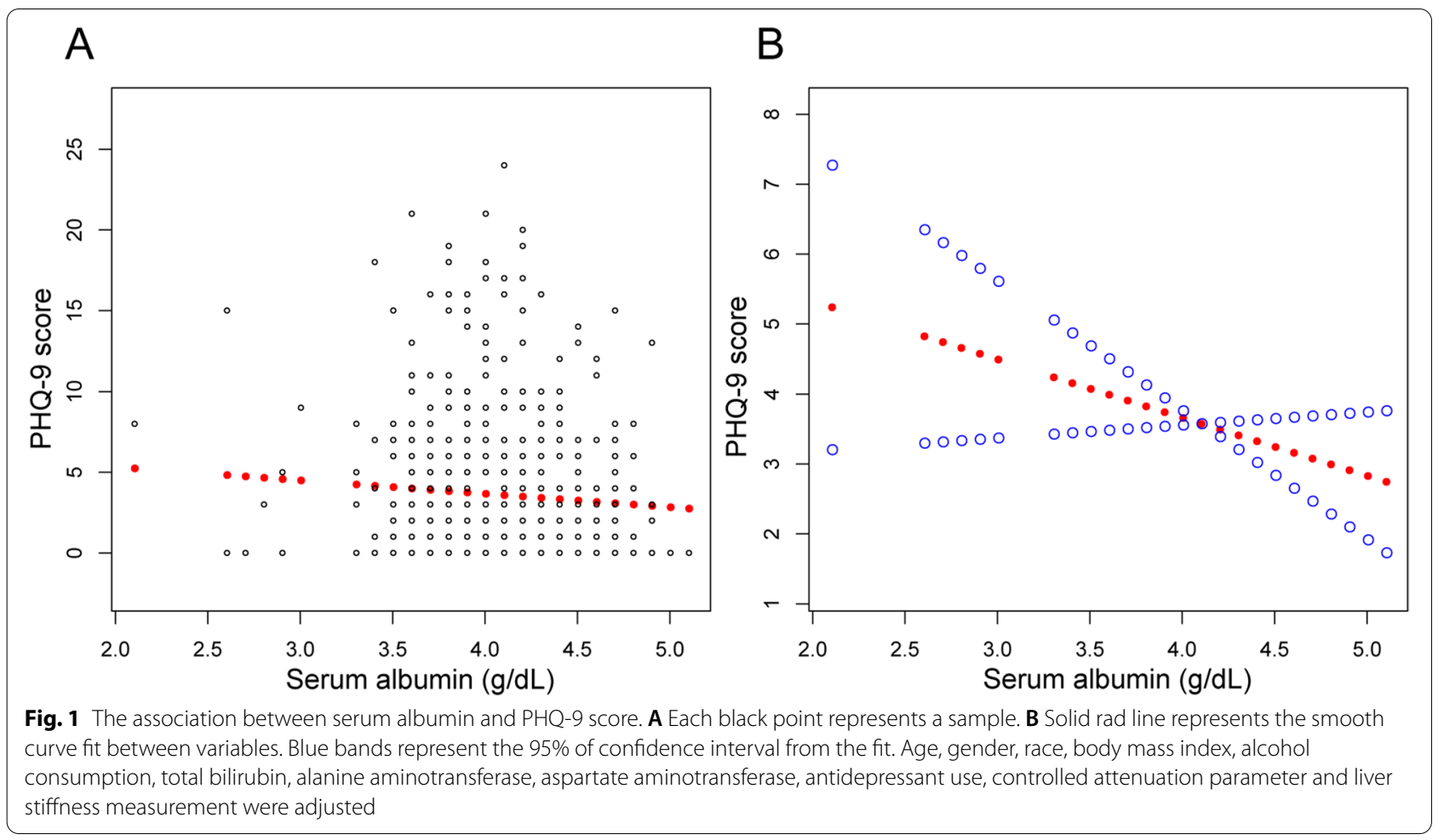


Table 3 Association between serum albumin level ( $\mathrm{g} / \mathrm{dL}$ ) and PHQ-9 score, stratified by gender, CAP and LSM

\begin{tabular}{|c|c|c|c|}
\hline & $\begin{array}{l}\text { Unadjusted model } \\
\beta(95 \% \mathrm{Cl}) P \text {-value }\end{array}$ & $\begin{array}{l}\text { Model } 1 \\
\beta(95 \% \mathrm{Cl}) P \text {-value }\end{array}$ & $\begin{array}{l}\text { Model } 2 \\
\beta(95 \% \mathrm{Cl}) P \text {-value }\end{array}$ \\
\hline \multicolumn{4}{|c|}{ Stratified by gender } \\
\hline Male & $-0.987(-2.200,0.227) 0.1119$ & $-0.848(-2.167,0.470) 0.2082$ & $-0.511(-1.802,0.779) 0.4380$ \\
\hline Female & $-1.824(-3.135,-0.514) 0.0068$ & $-2.033(-3.371,-0.694) 0.0032$ & $-2.002(-3.515,-0.489) 0.0100$ \\
\hline \multicolumn{4}{|c|}{ Stratified by CAP } \\
\hline$<274 \mathrm{~dB} / \mathrm{m}$ & $-2.491(-3.684,-1.299)<0.0001$ & $-1.809(-3.098,-0.521) 0.0064$ & $-2.215(-3.621,-0.808) 0.0023$ \\
\hline$\geq 274 \mathrm{~dB} / \mathrm{m}$ & $-1.180(-2.349,-0.011) 0.0485$ & $-0.982(-2.230,0.266) 0.1238$ & $-0.315(-1.597,0.968) 0.6309$ \\
\hline \multicolumn{4}{|c|}{ Stratified by LSM } \\
\hline$<8.2 \mathrm{kPa}$ & $-1.556(-2.524,-0.588) 0.0017$ & $-1.075(-2.108,-0.042) 0.0419$ & $-0.320(-1.381,0.741) 0.5547$ \\
\hline$\geq 8.2 \mathrm{kPa}$ & $-2.453(-4.325,-0.581) 0.0114$ & $-2.294(-4.334,-0.253) 0.0294$ & $-4.074(-6.237,-1.911) 0.0003$ \\
\hline
\end{tabular}

Unadjusted model: no covariates were adjusted

Model 1: age, gender and race were adjusted

Model 2: age, gender, race, body mass index, alcohol consumption, total bilirubin, alanine aminotransferase, aspartate aminotransferase, antidepressant use, controlled attenuation parameter and liver stiffness measurement were adjusted

In the subgroup analysis, the model is not adjusted for the stratification variable itself

CAP controlled attenuation parameter, LSM liver stiffness measurement

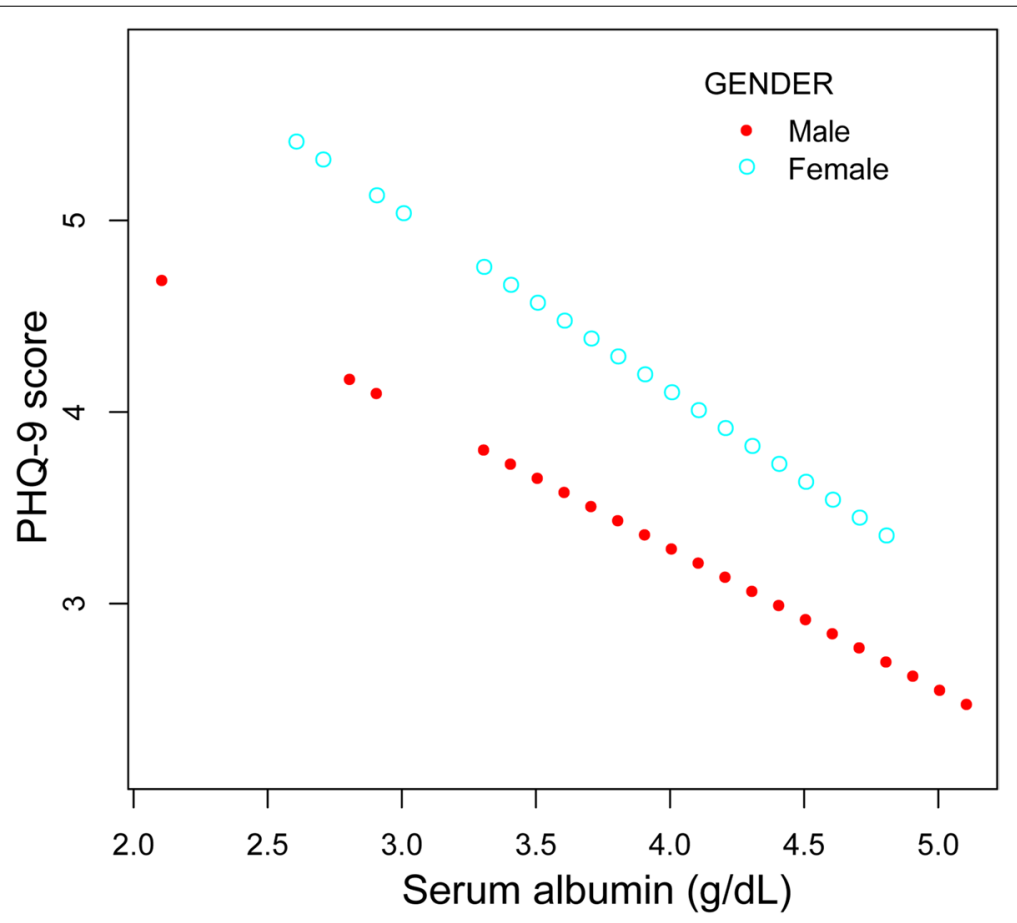

Fig. 2 The association between serum albumin and PHQ-9 score, stratified by gender. Age, race, body mass index, alcohol consumption, total bilirubin, alanine aminotransferase, aspartate aminotransferase, antidepressant use, controlled attenuation parameter and liver stiffness measurement were adjusted

explore the association between serum albumin and depression and take the influence of liver histology into consideration.

Our subgroup analysis showed that the association between serum albumin and depression was not significant among patients with $\mathrm{CAP} \geq 274 \mathrm{~dB} / \mathrm{m}$. As excess lipid accumulates in the cytoplasm, it could disrupt the cell constituent. The liver function is progressively compromised and various biochemical parameters, including alkaline phosphatase (ALP), AST, ALT and TB, would become abnormal. It has been reported that high bilirubin level was associated with depression [38]. Elevated 


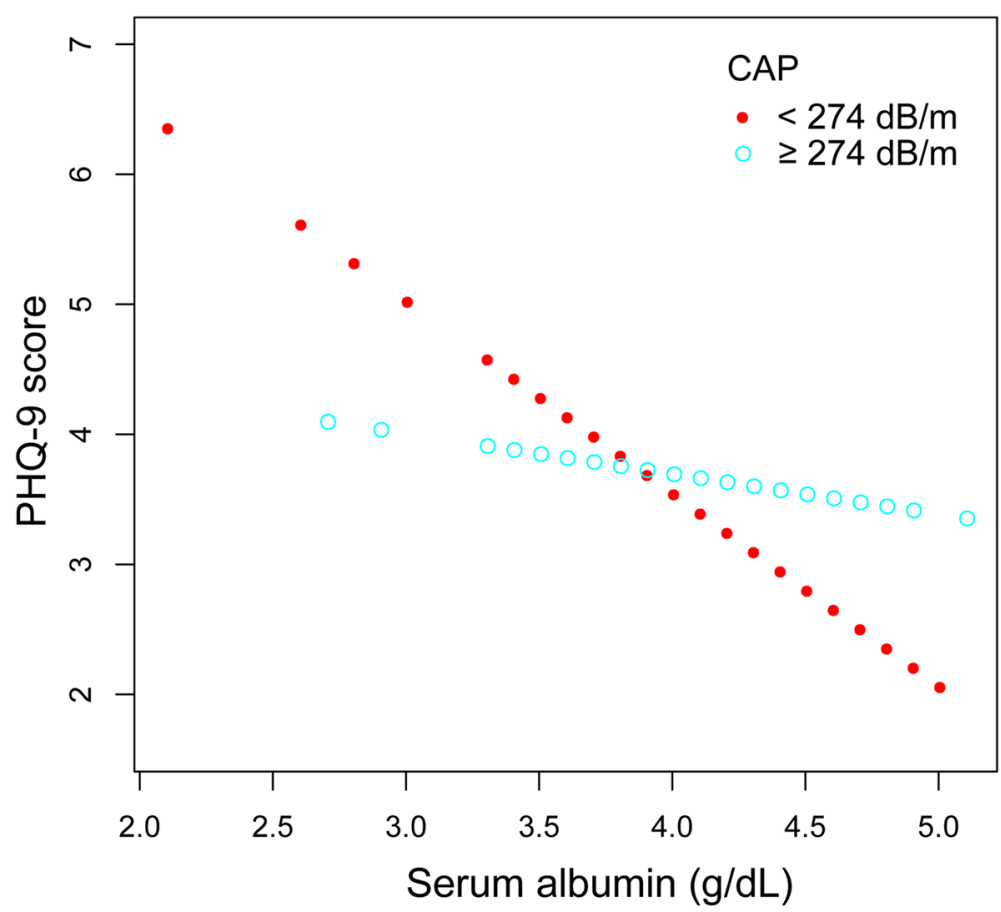

Fig. 3 The association between serum albumin and PHQ-9 score, stratified by controlled attenuation parameter. Age, gender, race, body mass index, alcohol consumption, total bilirubin, alanine aminotransferase, aspartate aminotransferase, antidepressant use and liver stiffness measurement were adjusted

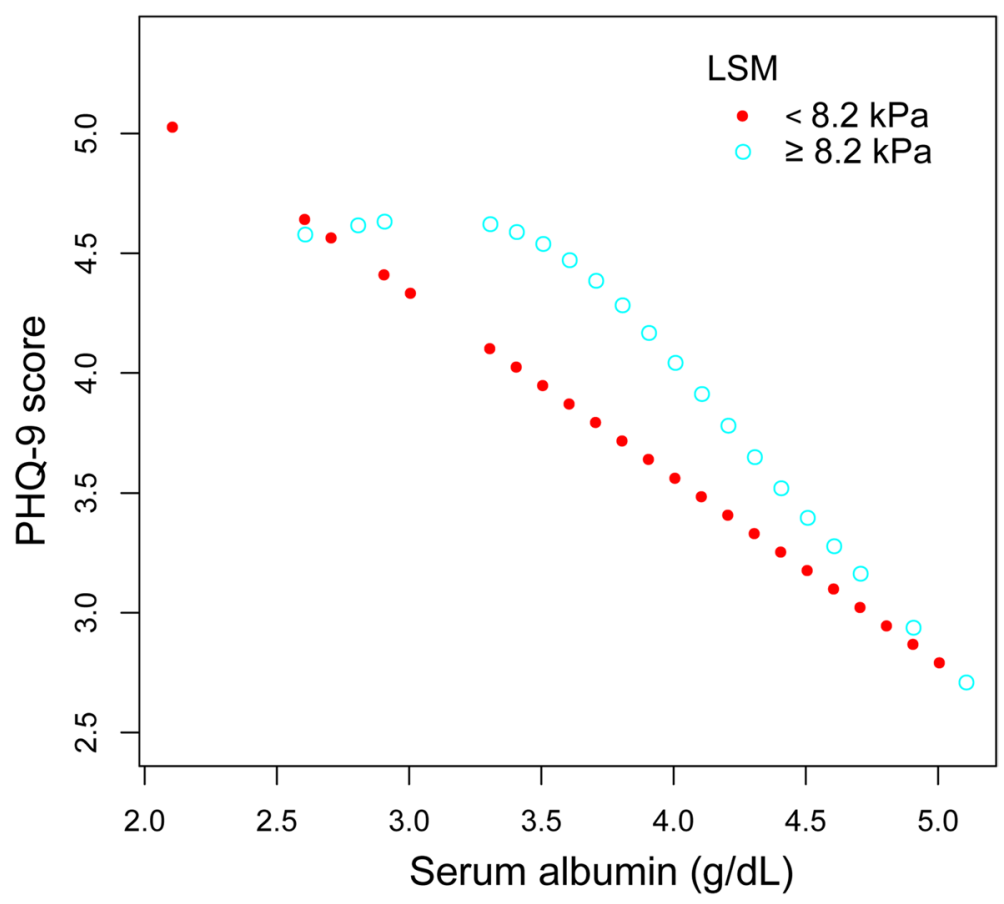

Fig. 4 The association between serum albumin and PHQ-9 score, stratified by liver stiffness measurement. Age, gender, race, body mass index, alcohol consumption, total bilirubin, alanine aminotransferase, aspartate aminotransferase, antidepressant use and controlled attenuation parameter were adjusted 
ALT was found in adolescents with NAFLD who developed depression [39] and it was also a significant independent predictor for the occurrence of minor and major depression in adults [40]. Moreover, depression would escalate the histological changes in reverse, probably through the monoamine oxidase-A enzyme pathway [10]. These findings indicate that there might be more complicated mechanisms contributing to depression in liver steatosis. On the other hand, the category of CLD was not included in regression model as it did not satisfy the criteria of covariate selection, which could be partly due to relatively small sample size of each CLD category and its limited impact to exposure coefficient. We believed that there could be specific and complicated mechanisms underlying depression for each CLD category at the stage of liver steatosis. It is highly recommended to launch rigorous prospective cohort studies or molecular biological researches to address this question. Nevertheless, our result still make sense because it corroborate serum albumin as a potential early warning biomarker of depression in CLD patients.

Serum albumin is closely related with liver fibrosis and the albumin platelet product has been validated in liver fibrosis staging [41]. Furthermore, the functions of serum albumin, such as antioxidant and detoxification capacity and the ability to chelate metal ions, were compromised in patients with cirrhosis [42]. The dysfunction of binding toxic metabolites and inflammatory mediators potentially affects the systemic inflammation and antioxidant activities. For example, elevated free serum levels of inflammatory cytokines can affect the activation of indoleamine 2,3-dioxygenase and the degradation of tryptophan along the kynurenine pathway, and ultimately leads to reduction in the synthesis and availability of 5-hydroxytryptamine [43]. This process has been reported to be involved in the pathophysiology of major depressive disorder and suicide [44].

Meanwhile, serum albumin exerts as plasma expander as well, attributed to its oncotic power. Hypoalbuminemia occurring in patients with liver fibrosis and cirrhosis endangered effective blood volume and impaired intestinal mucosal barrier, resulting in translocation of bacteria or bacterial products and local inflammation [45]. In chronically stressed mice, the reduction of Lactobacillus-derived reactive oxygen species may undermine the inhibition of indoleamine 2,3-dioxygenase and consequently increase the conversion of tryptophan to kynurenine in the intestine, which is able to traverse the blood brain barrier and linked to depression-like behavioral alterations [46]. Besides, excessive production of indole derivatives by the gut bacteria have shown neurodepressive properties [47], suggesting that microbiota dysbiosis may have an essential role in changing the functions of gut-brain axis. These may explain why the association between serum albumin and depression was significant at fibrosis stage.

Another notable discovery of our study is that there is a point of inflection and the association is much stronger when the serum albumin is higher than $3.4 \mathrm{~g} / \mathrm{dL}$ among patients with $L S M \geq 8.2 \mathrm{kPa}$. The structural integrity of albumin is vulnerable to systemic inflammation and oxidative stress as occurs in liver fibrosis and cirrhosis [48]. Oxidative damage of the cysteine-34 residue is the most common alteration [49]. Then the concept of "effective albumin concentration" has been brought into recently [50]. The proportion of albumin with complete structure and function is much lower than the measured concentration of serum albumin. The inflected point at $3.4 \mathrm{~g} /$ $\mathrm{dL}$ may suggest that the "effective albumin" decrease and reach to a "floor effect" quite early even when the measured albumin has a nearly normal level.

It is well known that the serum albumin concentration can be influenced not only by dietary protein consumed but also by capillary leakage. On the other hand, albumin levels can decline rapidly particularly in patients with advanced fibrosis and cirrhosis because of reduced synthesis by hepatocytes. However, the confounding effects of these factors could not be controlled for the present study yet. Therefore, our results need to be interpreted with caution and further study in large population is necessary to explore whether there is significant association between serum albumin and depression in each stage of liver fibrosis.

It is noteworthy that there are some limitations in the present study. First, this study is a cross-sectional research; thus, it is unclear whether there is a causal association between serum albumin and depression among CLD patients. Second, the sample size of this study is relatively small. Although the smooth fitting curves of male and female have similar tendency, only significant association was found in female. Because of limited sample size, participants with $L S M \geq 8.2 \mathrm{kPa}$ were not divided with advanced fibrosis and cirrhosis and we used only one threshold to define liver fibrosis although we agree with that thresholds for a certain fibrosis stage do differ with different etiologies. Hence, further studies with larger sample are needed to identify the association in different gender, different fibrosis stage and different etiologies. Third, there remains the possibility of bias caused by other confounding factors that were not included in this study.

\section{Conclusion}

The present study suggests an inverse linear association between serum albumin and depressive symptoms in CLD patients. In particular, the inverse association may 
be limited among patients with $\mathrm{CAP}<274 \mathrm{~dB} / \mathrm{m}$ and patients with $\mathrm{LSM} \geq 8.2 \mathrm{kPa}$, suggesting that this association was varied in different liver histological stages. This finding supports that serum albumin could be regarded as a warning marker for depressive symptoms in CLD patients, and that several strategies such as protein supplementation and dietary modification could be taken to against the risk of depression. Further prospective cohort studies are warranted to confirm the role of serum albumin in depression among CLD patients.

\section{Acknowledgements}

None.

\section{Authors' contributions}

JC and ZC designed the study; ZC was responsible for acquisition of funding for the study; HW was responsible for data sorting; NL and YY conducted data analysis; JC and WQ wrote the original draft of the manuscript; ZC directed the study and revised the manuscript. The author(s) read and approved the final manuscript.

\section{Funding}

This work was supported by the National Natural Science Foundation of China (No. 81401869).

\section{Availability of data and materials}

The datasets analyzed during the present study were provided at the National Center for Health Statistics at the Centers for Disease Control. https://www cdc.gov/nchs/nhanes/index.htm

\section{Declarations}

\section{Ethics approval and consent to participate}

The datasets analyzed during the current study was derived from the survey of National Center for Health Statistics at the Centers for Disease Control, which was approved by the ethics review board of the National Center for Health Statistics. All methods of this study were performed in accordance with the Declaration of Helsinki and relevant guidelines and regulations.

\section{Consent for publication}

Not applicable.

\section{Competing interests}

The authors declared that they have no competing interests.

\section{Author details}

${ }^{1}$ Department of Medical Ultrasonics, The Third Affiliated Hospital of Sun Yatsen University, Sun Yat-sen University, 600 Tianhe Road, Guangzhou 510630, China. ${ }^{2}$ Department of Rehabilitation Medicine, The Third Affiliated Hospital of Sun Yat-sen University, Sun Yat-sen University, 600 Tianhe Road, Guangzhou 510630, China.

Received: 31 July 2021 Accepted: 6 December 2021

Published online: 04 January 2022

\section{References}

1. Asrani SK, Devarbhavi H, Eaton J, Kamath PS. Burden of liver diseases in the world. J Hepatol. 2019;70(1):151-71.

2. Maeso-Diaz R, Gracia-Sancho J. Aging and chronic liver disease. Semin Liver Dis. 2020;40(4):373-84

3. Fletcher NF, McKeating JA. Hepatitis $C$ virus and the brain. J Viral Hepat. 2012;19(5):301-6.

4. Karaivazoglou K, Iconomou G, Triantos C, Hyphantis T, Thomopoulos K, Lagadinou M, et al. Fatigue and depressive symptoms associated with chronic viral hepatitis patients. Health-related quality of life (HRQOL). Ann Hepatol. 2010;9(4):419-27.

5. Mirabdolhagh Hazaveh M, Dormohammadi Toosi T, Nasiri Toosi M, Tavakoli A, Shahbazi F. Prevalence and severity of depression in chronic viral hepatitis in Iran. Gastroenterol Rep. 2015;3(3):234-7.

6. Altindag A, Cadirci D, Sirmatel F. Depression and health related quality of life in non-cirrhotic chronic hepatitis B patients and hepatitis B carriers. Neurosciences. 2009;14(1):56-9.

7. Jinjuvadia R, Jinjuvadia C, Puangsricharoen P, Chalasani N, Crabb DW Liangpunsakul S, et al. Evolving alcoholic hepatitis treatment C: concomitant psychiatric and nonalcohol-related substance use disorders among hospitalized patients with alcoholic liver disease in the United States. Alcohol Clin Exp Res. 2018;42(2):397-402.

8. Weinstein AA, Kallman Price J, Stepanova M, Poms LW, Fang Y, Moon J, et al. Depression in patients with nonalcoholic fatty liver disease and chronic viral hepatitis B and C. Psychosomatics. 2011;52(2):127-32.

9. Tomeno W, Kawashima K, Yoneda M, Saito S, Ogawa Y, Honda Y, et al. Non-alcoholic fatty liver disease comorbid with major depressive disorder: the pathological features and poor therapeutic efficacy. J Gastroenterol Hepatol. 2015;30(6):1009-14.

10. Youssef NA, Abdelmalek MF, Binks M, Guy CD, Omenetti A, Smith AD, et al. Associations of depression, anxiety and antidepressants with histological severity of nonalcoholic fatty liver disease. Liver Int. 2013;33(7):1062-70.

11. GBD. Global, regional, and national incidence, prevalence, and years lived with disability for 354 diseases and injuries for 195 countries and territories, 1990-2017: a systematic analysis for the global burden of disease study 2017. Lancet. 2018;392(10159):1789-858.

12. DiMatteo MR, Lepper HS, Croghan TW. Depression is a risk factor for noncompliance with medical treatment: meta-analysis of the effects of anxiety and depression on patient adherence. Arch Intern Med. 2000;160(14):2101-7.

13. Maes M, Wauters A, Neels H, Scharpe S, Van Gastel A, D'Hondt P, et al. Total serum protein and serum protein fractions in depression: relationships to depressive symptoms and glucocorticoid activity. J Affect Disord. 1995:34(1):61-9.

14. Pascoe MC, Skoog I, Blomstrand C, Linden T. Albumin and depression in elderly stroke survivors: an observational cohort study. Psychiatry Res. 2015:230(2):658-63.

15. Chen S, Xia HS, Zhu F, Yin GZ, Qian ZK, Jiang CX, et al. Association between decreased serum albumin levels and depressive symptoms in patients with schizophrenia in a Chinese Han population: a pilot study. Psychiatry Res. 2018;270:438-42.

16. Hung KC, Wu CC, Chen HS, Ma WY, Tseng CF, Yang LK, et al. Serum IL-6, albumin and co-morbidities are closely correlated with symptoms of depression in patients on maintenance haemodialysis. Nephrol Dial Transplant. 2011;26(2):658-64

17. Elwing JE, Lustman PJ, Wang HL, Clouse RE. Depression, anxiety, and nonalcoholic steatohepatitis. Psychosom Med. 2006;68(4):563-9.

18. Castera L, Friedrich-Rust M, Loomba R. Noninvasive assessment of liver disease in patients with nonalcoholic fatty liver disease. Gastroenterology. 2019;156(5):1264-1281 e1264.

19. Hartl J, Wehmeyer MH, Pischke S. Acute Hepatitis E: Two Sides of the Same Coin. Viruses. 2016:8(11):299.

20. Eddowes PJ, Sasso M, Allison M, Tsochatzis E, Anstee QM, Sheridan D, et al. Accuracy of FibroScan controlled attenuation parameter and liver stiffness measurement in assessing steatosis and fibrosis in patients with nonalcoholic fatty liver disease. Gastroenterology. 2019;156(6):1717-30.

21. Ren X, Xia S, Zhang L, Li R, Zhou W, Ji R, et al. Analysis of liver steatosis analysis and controlled attenuation parameter for grading liver steatosis in patients with chronic hepatitis B. Quant Imaging Med Surg. 2021;11(2):571-8

22. Xu L, Lu W, Li P, Shen F, Mi YQ, Fan JG. A comparison of hepatic steatosis index, controlled attenuation parameter and ultrasound as noninvasive diagnostic tools for steatosis in chronic hepatitis B. Dig Liver Dis. 2017;49(8):910-7.

23. Moreno C, Mueller S, Szabo G. Non-invasive diagnosis and biomarkers in alcohol-related liver disease. J Hepatol. 2019;70(2):273-83.

24. Tsochatzis EA, Gurusamy KS, Ntaoula S, Cholongitas E, Davidson BR, Burroughs AK. Elastography for the diagnosis of severity of fibrosis in chronic liver disease: a meta-analysis of diagnostic accuracy. J Hepatol. 2011:54(4):650-9. 
25. Lee K, Otgonsuren M, Younoszai Z, Mir HM, Younossi ZM. Association of chronic liver disease with depression: a population-based study. Psychosomatics. 2013;54(1):52-9.

26. Surdea-Blaga T, Dumitrascu DL. Depression and anxiety in nonalcoholic steatohepatitis: is there any association? Rom J Intern Med. 2011;49(4):273-80.

27. Poudel-Tandukar K, Jacelon CS, Bertone-Johnson ER, Palmer PH, Poudel KC. Serum albumin levels and depression in people living with human immunodeficiency virus infection: a cross-sectional study. J Psychosom Res. 2017;101:38-43.

28. Ambrus L, Westling $S$. Inverse association between serum albumin and depressive symptoms among drug-free individuals with a recent suicide attempt. Nordic J Psychiatry. 2019;73(4-5):229-32.

29. Maes M, Mihaylova I, Kubera M, Leunis JC, Geffard M. IgM-mediated autoimmune responses directed against multiple neoepitopes in depression: new pathways that underpin the inflammatory and neuroprogressive pathophysiology. J Affect Disord. 2011;135(1-3):414-8.

30. Rybka J, Kedziora-Kornatowska K, Banas-Lezanska P, Majsterek I, Carvalho LA, Cattaneo A, et al. Interplay between the pro-oxidant and antioxidant systems and proinflammatory cytokine levels, in relation to iron metabolism and the erythron in depression. Free Radic Biol Med. 2013;63:187-94.

31. Pomara N, Bruno D, Sarreal AS, Hernando RT, Nierenberg J, Petkova E, et al. Lower CSF amyloid beta peptides and higher F2-isoprostanes in cognitively intact elderly individuals with major depressive disorder. Am J Psychiatry. 2012;169(5):523-30.

32. Gao SF, Qi XR, Zhao J, Balesar R, Bao AM, Swaab DF. Decreased NOS1 expression in the anterior cingulate cortex in depression. Cereb Cortex. 2013;23(12):2956-64.

33. Roche M, Rondeau P, Singh NR, Tarnus E, Bourdon E. The antioxidant properties of serum albumin. FEBS Lett. 2008;582(13):1783-7.

34. Loban A, Kime R, Powers H. Iron-binding antioxidant potential of plasma albumin. Clin Sci. 1997;93(5):445-51.

35. Unalp-Arida A, Ruhl CE. Liver fat scores predict liver disease mortality in the United States population. Aliment Pharmacol Ther. 2018;48(9):1003-16

36. Lee JH, Kim D, Kim HJ, Lee CH, Yang Jl, Kim W, et al. Hepatic steatosis index: a simple screening tool reflecting nonalcoholic fatty liver disease. Dig Liver Dis. 2010;42(7):503-8.

37. Vallet-Pichard A, Mallet V, Nalpas B, Verkarre V, Nalpas A, Dhalluin-Venier $\checkmark$, et al. FIB-4: an inexpensive and accurate marker of fibrosis in HCV infection. Comparison with liver biopsy and fibrotest. Hepatology. 2007:46(1):32-6.

38. Tang WK, Liang H, Chu WC, MokV, Ungvari GS, Wong KS. Association between high serum total bilirubin and post-stroke depression. Psychiatry Clin Neurosci. 2013;67(4):259-64.

39. Noon SL, D’Annibale DA, Schwimmer MH, Shiels J, Arin J, Durelle J, et al. Incidence of depression and anxiety in a cohort of adolescents with nonalcoholic fatty liver disease. J Pediatr Gastroenterol Nutr. 2021;72(4):579-83.

40. Zelber-Sagi S, Toker S, Armon G, Melamed S, Berliner S, Shapira I, et al. Elevated alanine aminotransferase independently predicts new onset of depression in employees undergoing health screening examinations. Psychol Med. 2013;43(12):2603-13.

41. Fujita K, Yamasaki K, Morishita A, Shi T, Tani J, Nishiyama N, et al. Albumin platelet product as a novel score for liver fibrosis stage and prognosis. Sci Rep. 2021;11(1):5345.

42. Jalan R, Schnurr K, Mookerjee RP, Sen S, Cheshire L, Hodges S, et al. Alterations in the functional capacity of albumin in patients with decompensated cirrhosis is associated with increased mortality. Hepatology. 2009;50(2):555-64.

43. Milaneschi Y, Allers KA, Beekman ATF, Giltay EJ, Keller S, Schoevers RA, et al. The association between plasma tryptophan catabolites and depression: the role of symptom profiles and inflammation. Brain Behav Immun. 2021;97:167-75.

44. Messaoud A, Rym M, Wahiba D, Neffati F, Najjar MF, Gobbi G, et al. Investigation of the relationship among cortisol, pro-inflammatory cytokines, and the degradation of tryptophan into kynurenine in patients with major depression and suicidal behavior. Curr Top Med Chem. 2021:21. https://doi.org/10.2174/1568026621666210909160210.
45. Bernardi M, Angeli P, Claria J, Moreau R, Gines P, Jalan R, et al. Albumin in decompensated cirrhosis: new concepts and perspectives. Gut. 2020;69(6):1127-38.

46. Marin IA, Goertz JE, Ren T, Rich SS, Onengut-Gumuscu S, Farber E, et al. Microbiota alteration is associated with the development of stressinduced despair behavior. Sci Rep. 2017;7:43859.

47. Jaglin M, Rhimi M, Philippe C, Pons N, Bruneau A, Goustard B, et al. Indole, a signaling molecule produced by the gut microbiota, negatively impacts emotional behaviors in rats. Front Neurosci. 2018:12:216.

48. Claria J, Stauber RE, Coenraad MJ, Moreau R, Jalan R, Pavesi M, et al. Systemic inflammation in decompensated cirrhosis: characterization and role in acute-on-chronic liver failure. Hepatology. 2016;64(4):1249-64.

49. Oettl K, Birner-Gruenberger R, Spindelboeck W, Stueger HP, Dorn L, Stadlbauer $\mathrm{V}$, et al. Oxidative albumin damage in chronic liver failure: relation to albumin binding capacity, liver dysfunction and survival. J Hepatol. 2013;59(5):978-83.

50. Jalan R, Bernardi M. Effective albumin concentration and cirrhosis mortality: from concept to reality. J Hepatol. 2013;59(5):918-20.

\section{Publisher's Note}

Springer Nature remains neutral with regard to jurisdictional claims in published maps and institutional affiliations.
Ready to submit your research? Choose BMC and benefit from:

- fast, convenient online submission

- thorough peer review by experienced researchers in your field

- rapid publication on acceptance

- support for research data, including large and complex data types

- gold Open Access which fosters wider collaboration and increased citations

- maximum visibility for your research: over $100 \mathrm{M}$ website views per year

At BMC, research is always in progress.

Learn more biomedcentral.com/submissions 